Psychology of Language and Communication 2021, Vol. 25, No. 1

\title{
Sciendo
}

DOI: $10.2478 /$ plc-2021-0010

\author{
Susana Amante ${ }^{1}$, Maria José Antunes ${ }^{2}$, Magdalena Dygala ${ }^{3}$, Illkay Gökçe $e^{4}$ \\ ${ }^{1}$ School of Technology and Management, and CI\&DEI, at the Polytechnic of \\ Viseu, Portugal, \\ ${ }^{2}$ School of Technology and Management, and CISeD, Polytechnic of Viseu, \\ Portugal \\ ${ }^{3}$ Kazimierz Pulaski University of Technology and Humanities, Radom, Poland \\ ${ }^{4}$ Ege University, Izmir, Turkey
}

\section{Stepping up to Global Challenges (SGC): Empowering Students across the World}

\begin{abstract}
Stepping up to Global Challenges (SGC) aimed to provide students with opportunities for language practice through task-based learning activities and the use of digital platforms for interaction. Marketing students at the Polytechnic of Viseu, Portugal, collaborated with peers from Poland and Turkey, choosing an image on entrepreneurship and posting it on the SGC Facebook page to solicit comments from their own and other groups. This was one of the tasks assigned during the 2nd semester of 2019/20, under the constraints of COVID-19. We analyzed the students' choices, main difficulties, and motivation to persist in learning and improving their skills to share knowledge with (inter)national peers.
\end{abstract}

Key words: project-based language learning; entrepreneurship; English for specific purposes (ESP); COVID-19

Address for correspondence: Susana Amante, School of Technology and Management, Polytechnic of Viseu, Portugal.

E-mail: susanamante@estgv.ipv.pt

This is an open access article licensed under the CC BY NC ND 4.0 License. 
Because PBL uses an assortment of methods associated with student engagement - active, collaborative, studentcentered, and self-directed learning focused on realistic problems and authentic assessments-we might expect that it would lead to increased student engagement.

(Allen et al., 2011, p. 26)

The authors of the present study, all teachers of English as a foreign language (EFL), adopted the above epigraph as the motto of a project carried out in the second semester of 2020, which aimed, first of all, to create opportunities for students at the Polytechnic of Viseu, Portugal, at the Kazimierz Pulaski University of Technology and Humanities in Radom, Poland, and at Ege University School of Foreign Languages, Turkey, to engage in active - rather than passive-learning. Accordingly, in agreement with the view of the scholars quoted above on the positive effects of project-based learning (PBL), we created some guidelines for a project we came to entitle "Stepping up to Global Challenges (SGC): Empowering Students across the World." This reflects our belief that language mastery and intercultural communication are the best tools to enable students to speak up and step up to contemporary challenges at the heart of international affairs. Aided by technologies such as collaboration platforms and social media, which have become increasingly embedded into our lives, students of the socalled generation $\mathrm{Z}$ engaged and connected with the syllabus, felt much more involved, and co-constructed their knowledge in authentic situations.

In the next sections, we present the literature review that guided this study. Thus, we start by discussing the use of technologies in foreign language teaching, particularly by looking at telecollaboration and some social media as tools, then we highlight the importance of PBL, and we provide a glimpse of the determinants of successful entrepreneurship, because these topics help to define and frame the entire empirical research. This article aims to be a contribution to the field by examining the effectiveness of collaborative learning aided by technology to enhance English communicative competence among the higher education students from these three countries.

\section{Integrating Technologies and Project-Based Learning Into Foreign Language Teaching}

In this globalised and highly competitive world, a solid command of English is an essential requirement for those seeking a career in a business environment where cross-cultural encounters have become the norm. Therefore, in the classroom, EFL teachers should offer multiple opportunities for language practice and development in the classroom, involving students in authentic situations, in realistic contexts, that approximate the environment outside the walls of their higher education institutions. 
Students sometimes complain that most of the content taught throughout their coursework will not be applicable in their future professional lives. Thus, the main objective of a language class should not be to replicate rules or patterns but to improve oral and written communication effectively while developing critical thinking and problem solving. This can be facilitated in the modern classroom with information and communication technology (ICT), which creates interactive learning environments that overcome the traditional boundaries of the classroom and open doors to the world. As Díaz and Ioannou (2019, p. 1-2) point out:

The often-called twenty-first-century educational challenges include, among others, how to support hyperconnected people to develop skills such as problem-solving, creativity, critical thinking, collaboration and communication (...) - skills that people need for work, citizenship, and selfactualization in the twenty-first-century (...). Many of these skills have been around for decades if not centuries, but the way we acquire and apply them has dramatically changed due to our pervasive relationship with ICTs that are making our world more global and immediate.

Today's students are born with technologies at their fingertips, and they grow up in a world where they are just a few clicks away from any sort of information they need to research. Our world has become so increasingly interconnected through technology that, nowadays, the lines between study and entertainment, or work, leisure, and social life, have become blurred. The same happens in terms of physical distance because cyber borders are easily transcended, and virtual proximity enables cross-cultural interaction to occur. Today's digital natives, or generation Z, iGeneration, among so many other nomenclatures used (Giunta, 2017; Levickaite, 2010), are hyper-connected because, since they are born, they have access to a wide scale of digital communication technology - from broadband Internet connection at home to online access at educational institutions, the use of computers and computer games, mobile phones, social media, and different apps - and it certainly bridges peoples and cultures, facilitating a meaningful and purposeful exchange of ideas and a better knowledge about the Other and their cultures.

Bearing in mind that, " $[\mathrm{t}] \mathrm{o}$ establish relationships, they prefer social media to face-to-face communication" (Vizcaya-Moreno \& Pérez-Cañaveras, 2020, p. 1), their attention span is short (Giunta, 2017; Magano et al., 2020), they favour visual media and, thus, "visual forms of learning” (Poláková \& Klímová, 2019, p. 14), flexibility and "hands-on opportunities that prepare them for career success" (Seemiller \& Grace, 2017, p. 24), then, in education, this calls for the use of multiple content domains in a single lesson and invites a multidisciplinary approach with tasks that promote metacognition, interaction, learning and transfer. A very good approach that has proven successful is the introduction of virtual collaborative learning through telecollaboration, which can be defined as 
... the process of communicating and working together with other people or groups from different locations through online or digital communication tools (e.g., computers, tablets, cellphones) to co-produce a desired work output. Telecollaboration can be carried out in a variety of settings (classroom, home, workplace, laboratory) and can be synchronous or asynchronous. In education, telecollaboration combines all of these components with a focus on learning, social interaction, dialogue, intercultural exchange and communication all of which are especially important aspects of telecollaboration in language education.

(Dooly, 2017, pp. 169-170)

This all became much more pertinent when, due to the COVID-19 pandemic, lockdown measures were implemented worldwide, necessitating a shift to digital distance learning. Students confined to their homes were forced to adapt, cooperate, and gain the necessary skills to be successful.

Learning is precisely the act of co-constructing knowledge in which, according to a constructivist approach, students "continually test and modify these constructions in the light of new experience (...) and against a backdrop of shared understandings, practices, language and so forth" (Schwandt, 2000, p. 197). This is not new. Back in the late eighteenth century, the educational reformer Pestalozzi strongly discouraged rote learning and punishment as methods of teaching and emphasised the use of objects and activity instead, recognising the importance of practical experiences. This movement clearly influenced other reformers in other parts of the world, namely Dewey in America, who advocated "learning by doing" as an effective way to engage students and help them cope with emotions such as anxiety and fear of failure, while providing them with opportunities to take risks. Working in small groups, students can support classmates struggling with a particular task. Moreover, once students are required to delegate responsibility to others to complete different subtasks, they also acquire other fundamental skills such as assigning roles among group members, negotiating, and reaching consensus on all aspects of a project's process and product. These are the principles of PBL, in which the students are actively involved in the learning process, sharing knowledge while trying to answer authentic questions and problems derived from real-world contexts and, ultimately, putting together a final product that addresses the core challenge (Brassler \& Dettmers, 2017).

In light of the above, using social networking sites such as Facebook in educational environments to build telecollaborative communities of learners from different geographical and cultural contexts that work together to achieve a common goal comes as a natural step, following the experience gained over the last decade (Reinhardt, 2018). In fact, several studies have been conducted on the use of social networking platforms (see, e.g., Aydin, 2012; Blattner \& Fiori, 2013; Godwin-Jones, 2019; Leier, 2017; Promnitz-Hayashi, 2011; Reinhardt, 2018; ) and there is now widespread consensus on their effectiveness to 
... empower learners to see language learning as integral to real-world experiences and also help instructors to see the bigger picture of contributing to fighting stereotypes, encouraging empathy, and working toward social justice. (...) Through social participation, individual autonomy is enhanced, language skills are developed, and personal identity is expanded.

(Godwin-Jones, 2019, p. 19)

The use of social media, and Facebook in particular, may be an effective means to engage the students, monitor their learning while ensuring that social purposes are held. Students become more active participants, being easily connected with (inter)national peers and teachers, sharing ideas and resources that go well beyond the coursebook or traditional assignments to have them expressing themselves and interacting in authentic, real-life situations. As Grabill and Hicks $(2005$, p. 306) put it, "If we want to (...) help students learn how to write more effectively, then we have to see writing in the same ways that they do and be with them where they write." If they use the Internet and social platforms to create and share information, then "[n]etworks [become] classrooms. Digital writing is socially situated in a collaborative, recursive and responsive space in which teachers must participate with their students" (p. 306). The same holds true when it comes to the development of other skills, such as listening, speaking and reading.

All this has become even more meaningful since the rise of the COVID-19 pandemic because the lockdown measures caused a long period of social isolation for students in many countries, and a means to cope with the lack of social contact was precisely through the use of social media. If being physically in classes was impossible, then keeping in touch with students through email, Facebook, or Messenger extended the remote learning period. Students could make distances shorter though technology and collaborate in projects open to international partners in a synergistic learning environment. Each one could contribute by bringing their knowledge, skills, and experience, getting ready for a future where one needs to cope with emotions, dealing with uncertainty and taking risks. These are very important entrepreneurial attributes that can be taught through the learning-by-doing approach. As Seemiller and Grace (2017, p. 24) remind us, these students are future workers "who engage in freelance work rather than (...) long-term contracts with one employer" and it means that they "know that they have a lot to learn about entrepreneurship as nearly two-thirds think that colleges and universities should teach students skills they can use to run a business..." Entrepreneurship education has been increasing, and pedagogies that promote experiential learning, that is, that are action-oriented, have been gaining an enormous amount of attention from academia and the business world alike. As Krüger and David (2020, p. 4) point out, "today, entrepreneurship is a crucial point for many disciplines, among them economics, sociology, and management, and it could become topic to further ones." Enterprising skills and 
behaviours, such as autonomy, confidence, divergent thinking and creativity, flexibility, and problem solving have been stimulated by immersion in real-life situations required by the PBL method in which students develop and pursue solutions to problems, ask and redefine questions, and share and debate ideas and findings, making the most of their hands-on experience, and, consequently, being empowered intellectually, emotionally, and socially.

This is the framework that underlies the present article. In the next few pages, we focus on the opportunities for language practice by marketing students studying at the Polytechnic of Viseu, Portugal through task-based learning activities and the use of digital platforms for interaction. The students' choices of images and videos, together with the messages or thoughts accompanying them, first by the groups making selections, and then by their peers in response, provide the foundation for us to identify the advantages of implementing PBL teaching in the future.

\section{Aims, Research Design, and Participants}

In this article, we intended to analyse the students' choices, main difficulties, and motivation to persist in learning and improving their skills to collaborate and share knowledge with (inter)national peers.

This study was a piece of exploratory research, relying on a descriptive, qualitative content analysis (QCA) methodology. Being a case study, we believe this allows the researchers to explore students' perceptions of their own learning while providing insights into their collaborative experience and co-construction of knowledge.

The participants in this project included two classes of undergraduate marketing students, taught by two professors at the Polytechnic of Viseu, Portugal; a class of Polish undergraduate students in English philology enrolled in writing classes at the Kazimierz Pulaski University of Technology and Humanities in Radom; students on a vocational course taking English at the Technical School of Electronics, also in Radom; and finally, first-year students, taking English while enrolled in psychological counselling and guidance at Ege University School of Foreign Languages in Turkey. This study, however, focused on the performance of marketing students in Business English II, although they were engaged in interaction with peers from the two other countries.

Each of the two Portuguese classes consisted of first-year students who had completed Business English I in the first semester of 2019-2020. The overall group consisted of 64 students, 30 male and 34 female, among whom four were from Montenegro, three from Brazil, and one from Holland. There was a total of 17 groups. With respect to their skill levels in English, based on lessons taught and evaluations from Business English I, the groups appeared heterogeneous, allowing for much improved performance than if each student worked individually. 


\section{Data Collection}

The primary data set in this study were the students' posts, one per group, for which they were required to select an image or video and write an accompanying sentence or paragraph. These had to be related to the topic of entrepreneurship and were to be posted on the private SGC Facebook page. By the day before a Zoom meeting, each student in each group was asked to have reflected on other groups' posts, that is, make as many comments to different posts as the number of students in each group (Task 1). Students were reminded that they were being assessed on the quality and depth of their comments as a group, not individually, which meant that agreement on content was required before posting. We thus encouraged fruitful interactions and a positive and supportive learning environment, allowing students to be aided and corrected by their peers outside traditional classroom boundaries.

We decided not to analyse the second task in this study - in which the students selected a Portuguese/Polish/Turkish company and collected information to make a video to present it, focusing on who founded it, when, how, why, the products or services it sells or supplies, its competitive advantage, and the strategies needed to adapt and cope with the global pandemic crisis. This task will support future research, since it alone allows us to understand how students work together, their language difficulties, and how they overcome them.

Video recordings of the students' interactions during a Zoom meeting (Task 3) with another group based in Turkey and/or Poland were employed to collect relevant, general information. This allowed us to more fully understand the students' rationale for using particular pictures or videos in Task 1 and, conversely, the reactions of the other groups toward them. The third task and the final report that each group submitted, reflecting upon the whole project, were considered here insofar as they were pertinent to Task 1.

\section{Data Analysis}

Data analysis consisted of the following three steps:

1. Open coding, which involved examining each group's prompt and accompanying text in order to establish categories.

2. Axial coding. Through comparison, we found commonalities in the data, looking for clues to understand how the main categories related to one another and how they portrayed the relationship between entrepreneurship (the overarching theme) and risk-taking, failure, education, creativity, and problem solving, among others. Even if some categories proved more general or subjective/abstract, or did not completely match the actual wording of the raw data, we found it helpful to integrate or restructure the data into broader clusters.

3. Identifying weaknesses in linguistic structure and usage, to facilitate further action and improvement in the short term 


\section{Results and Discussion}

As each student in a group was supposed to comment on another student's post, or respond to comments that they identified, wanted to contribute to, or contest, we collected around 100 posts and reactions by students studying at the Polytechnic Institute of Viseu. The majority consisted of verbal communication, meaning that they communicated ideas, while the remainder used nonverbal cues, in which emoticons conveyed emotional messages (Lo, 2008, p. 595).

The coding process identified five main categories, which ranged from "Educating toward entrepreneurship" to "Innate qualities predisposed to entrepreneurship," as well as "Entrepreneurship as translating ideas into action, or as a journey, or as taking steps to great achievements," "Entrepreneurship as creativity, innovation, and problem solving," and, finally, "Entrepreneurship as a social and political phenomenon." It was not easy to group all posts and reactions into these broader clusters or themes, as the complexity of interpreting the data meant that the researchers did not always reach a consensus. We believe, however, that conducting an individual analysis first, followed by discussion and negotiation, led us to a more balanced and coherent position that optimised clusters.

One of the most prominent clusters to emerge from the data concerned entrepreneurship as the pursuit of opportunities or dreams. In fact, many students referred to it as an action, as taking a leap, or step, embarking on a journey toward success. A post that attracted a significant number of likes and comments included the following quote from Ellen Langer, a professor of psychology who, among other areas such as aging and mindfulness, focuses on decision-taking: "There is always a step small enough from where we are to get us to where we want to be. If we take that small step, there's always another we can take, and eventually, a goal thought to be too far to reach becomes achievable" (Group 4). This was accompanied by a photograph taken by the group, showing how we can continue to be creative even in troubled times. As the group mentioned in their final, reflective report: "as a result of the pandemic, we were forced to take individual photos and put everything together using Photoshop. Our picture was based on evolution on men, but we adapted into the path of entrepreneurship" (Group 4).

The final result is presented below, and we believe it is interesting to highlight the fact that the students carefully considered every detail, particularly the use of colour: "We decided to use the gradient orange for the background of our image since orange suggests strength, succeed, ambition and stimulates our minds as entrepreneurs" (Group 4).

If Group 4 associated entrepreneurship with small steps, Group 7 went further and presented it as an arduous path to follow, implying intense commitment and performance: "The path of success is never easy because our victory is measured through our effort, hard work, patience, and our strength in not giving up. At the 


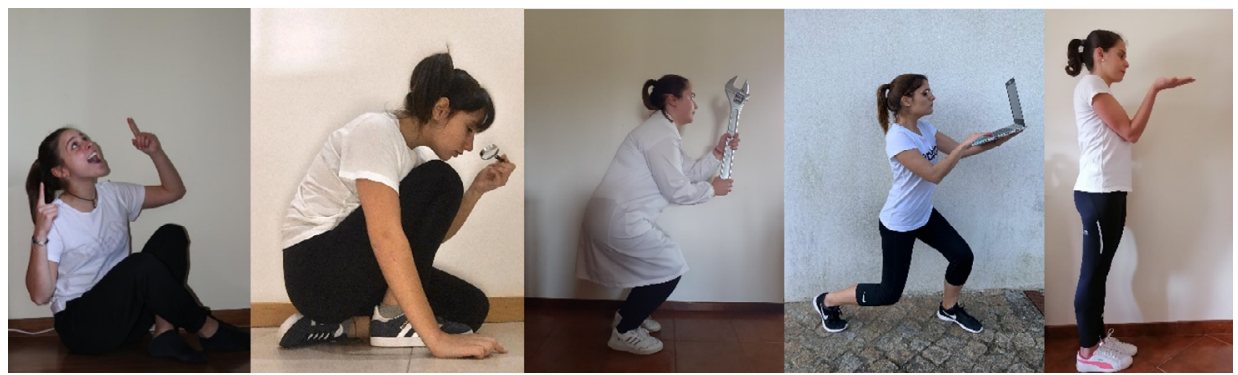

Figure 1. Remote collaboration in times of COVID-19 (Task 1, Group 4).

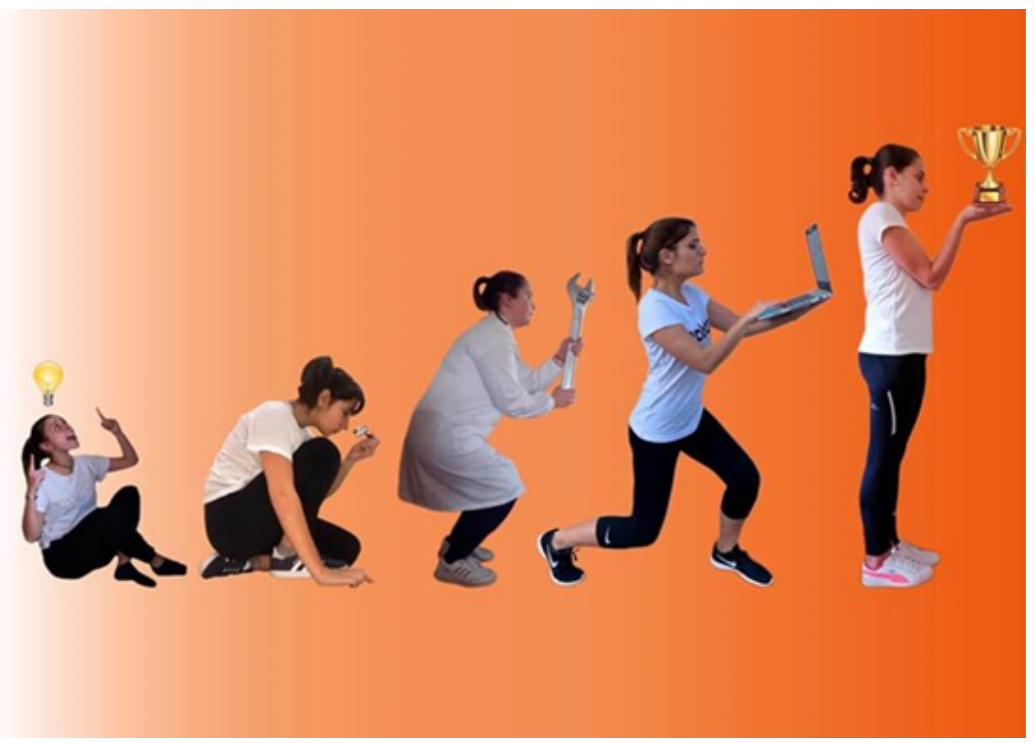

Figure 2. The path from having an idea to bringing it into being (Task 1, Group 4).

end of the path, we will realize how much we have learned during this journey and how much stronger we have become."

Still within the same cluster, but providing a glimpse of some of the innate characteristics that drive entrepreneurs to take risks, and sometimes to fail (a natural part of learning through trial and error), is this quote from Group 11:

Be an entrepreneur who, like a climber, doesn't give up until he reaches the top, and even if he falls there is always a way to climb again until he reaches his goal. In addition to trusting your own ability, you must accept the risks, be initiative, be persistente and do not give up at the first try (Group 11).

While emphasising the drive to action, the quote can also be understood as advice on how to pursue success, demonstrating traits such as self-confidence, persistence, or resilience, as well as being proactive and optimistic. The spelling 
and grammatical mistakes made by these students were not treated negatively, but as an opportunity for feedback, growth, and further development, following Başöz and Aydın's (2011) assertion that "the foreign language learning process cannot be separated from creating mistakes, and it is also possible to learn from grammatical mistakes if a teacher corrects them during and after the writing process" (p. 297). We shall return to this topic later in this study.

Making mistakes is a natural part not only of language learning, but of any learning process, as the post by Group 14 on the left indicates. This post generated a high response rate, with interesting comments such as "As Thomas Edison said 'I didn't fail 1000 times. The light bulb was an invention with 1000 steps', I tried a lot of new things" or "You could think 'oh you made a mistake you are so dumb' but in fact it is more like 'oh you learn something, you are now smarter' because you more likely will not make that mistake in the future. That surely proves how important is to learn from our mistakes." Among many others reflecting on the positive impact of mistakes, the following quote seeks to make sense of a mindset that punishes those who try and fail:

I think we are afraid of making mistakes because since we are little we are taught that things must be done well and if you don't you fail. But reality is not like that. I think that based on mistakes you learn. Sometimes it's frustrating but it can also be motivating, it depends how you look at it

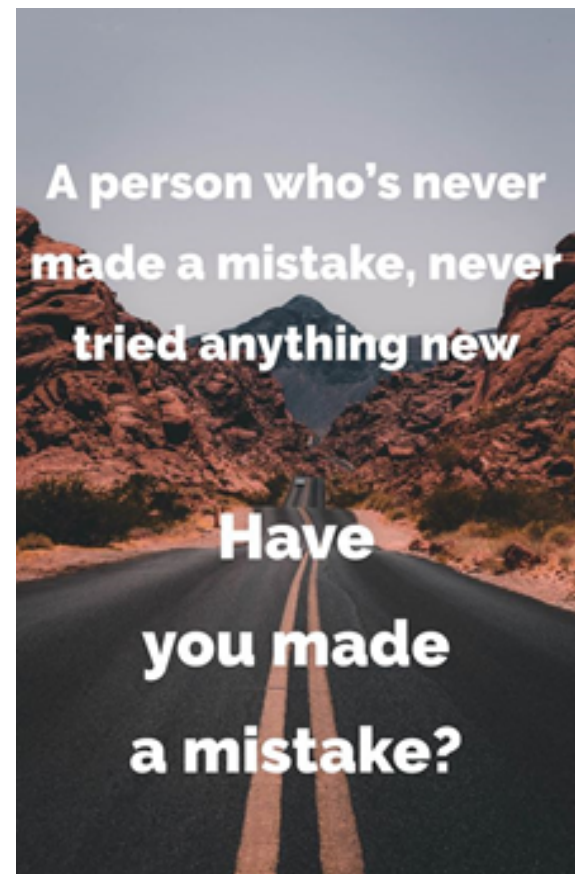


From a young age, children are taught to colour within the lines, and not necessarily for the purpose of coordination. Rather than developing fine motor skills, what underlies this is often compliance with social norms. This recalls Scarborough and Cornwall's observation that

[p]art of the problem is that deeply ingrained in most educational systems is the assumption that there is one 'right' answer to a problem. In reality, however, most problems are ambiguous. (...) Most education systems do not do much to encourage creativity among students; instead, they promote uniformity and standardization. People who go through many years of schooling often come out on the other side drained of their creative potential and focused on conformity rather than on creativity.

Creativity has not always been regarded positively and, as Moran (2010, p. 76) reminds us, it "is often associated with deviance, rebelliousness, daring, and independence (...): Creators 'go their own way' and may not be dependable or reliable. They hold different values" In the past, this could be sufficient for a creative individual to be thought of as a lunatic or insane.

Based on the idea that school devalues creativity - which Sir Ken Robinson shared, asking "Do Schools Kill Creativity?" in a TED Talk (2006) that went viral, Group 2 posted a picture questioning the value of school for entrepreneurs. Though this post could also fit in the cluster "Entrepreneurship as creativity, innovation and problem solving," we decided to include it within "Educating toward entrepreneurship," as the group returned to it in Task 3 . They proceeded to discuss the role of education in developing both human capital and the entrepreneurial spirit, a feature of all the courses across three different countries encompassed by the present study. The picture above was preceded by two questions: "Do you agree? Why?" and collected 28 comments and 40 likes, plus six reactions of love and one of surprise. Among these, some thought-provoking and stimulating examples deserve to be highlighted, as they provided us with additional references to follow up: "Education system can grow so much more and I would hope it grew around the internal personal growth skills. Gary Vaynerchuk has a lot on this subject!" and "read John Gatto, Weapons of Mass Instruction. The Turkish name is Eğitim Bir Kitle Imha Silahı." Furthermore, other comments drew analogies, such as between schools and prisons, in the sense that "both trap the body at certain times. The only way out of this is to make schools the source of creative thoughts." This comment was enlivened with supporting remarks, and another analogy, such as those posted below.

It is interesting to note that this last comment acknowledges recent changes in the educational system, and that the SGC project is cited as evidence of this. Rather than memorizing content, the purpose of education should be to provide students with the necessary tools for them to develop personal, social, and preprofessional skills that ultimately will allow them to participate actively in democratic life. School should 


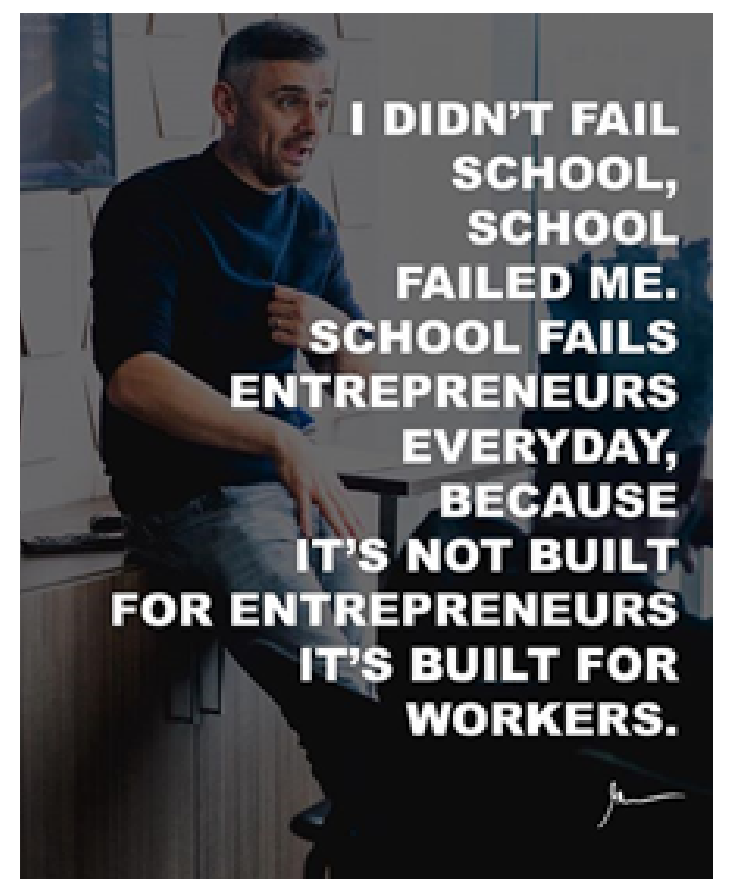

Figure 4. Post by Group 2 (Task 1).

thus help students gain knowledge and learn both autonomously and collaboratively, making connections between what they co-construct in the classroom and the real world

We now live in a society, more than merely a society of information, with technological progress inducing rapid change. Schools and universities need to adapt to this reality and respond to the fast pace with which the world is evolving. This becomes even more critical in times of distress, such as during the present coronavirus pandemic which has created unprecedented uncertainty and novel challenges in numerous fields, particularly the digital transformation and transition to remote learning and work, as previously described.

More than ever, we should all be lifelong learners; learning should be regarded as an ongoing process for everyone, and teachers should be facilitators guiding those who want to learn. As another student, representing his group, wisely pointed out: "Teachers open the door but you must walk through it yourself."

The students provided constant feedback on the project, to which teachers reacted, enhancing student engagement and meaningful learning, as this testimony from the group's Facebook page indicates: "It is interesting to see how this work has changed and influenced something in our lives. I'm sure it will mark our memories in a positive way for all this learning and new knowledge." Similar comments were made during the international virtual meeting and in final written reports, such as the following from Group 17: 


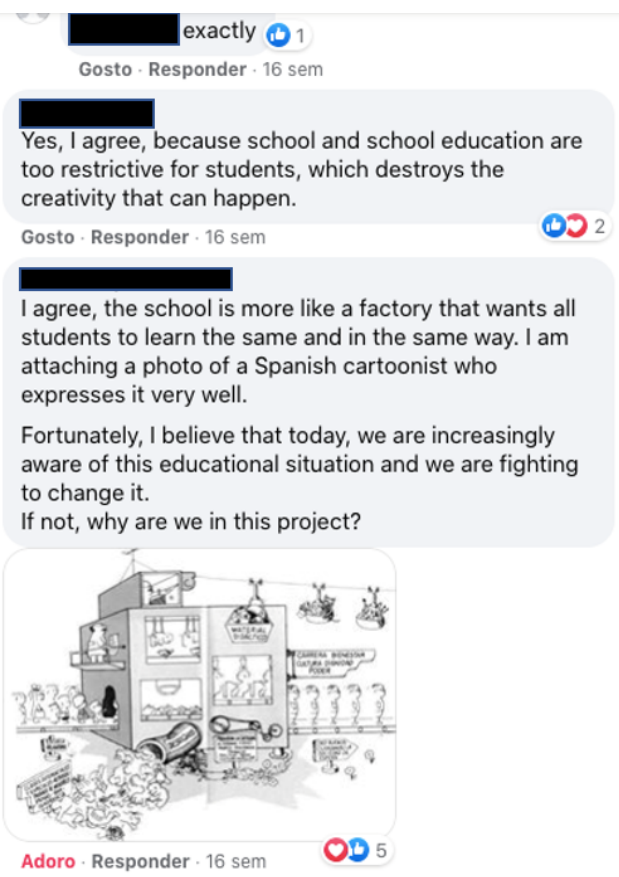

Figure 5. Individual reaction to a post (Task 1).

This was an amazing project where we were able to develop our skills in English, learn about an important entrepreneur in Portugal and meet our Turkish friends. We learned a lot from this project and will, now, review every task to talk about our development and our main difficulties. In Task 1 we did not have a major difficulty, it was easy to choose a sentence or a quote from all the posts. With this assignment, we could learn more about entrepreneurship and how it is viewed around the world, we understood that the main advice is that if you take action, if you leave your comfort zone and fight for your dreams it will be the only way to become successful. (...)

It is interesting to note that students took this opportunity to engage in a collegial process of learning and challenging their peers in these terms: "Many people think beeing an Entrepreneur is all about starting your company from ground zero and having a lot of innovative ideas, but is that really true?" (Group 3 , sic). We assigned this post to the cluster "Entrepreneurship as creativity, innovation and problem solving" because it problematises any clear-cut division between existing and new structures, products, or processes. The rhetorical question necessarily implies that newness and originality are built upon prior knowledge, as in a spiral. The underlying idea seems to be that students view entrepreneurship as related to creativity, but with a focus that depends on the ability to capitalize on existing resources and knowledge. This post gathered 32 
comments, 46 likes, and four reactions of love. Among the replies, we would like to highlight one mentioning that "There is no need to start a company to become an entrepreneur." Similarly, one participant studying in Poland, put it this way:

My opinion is no. You can be an entrepreneur in many areas of life, even at work without having to start your own company.

For example, I want to be teacher in a future, and I consider that teachers every day come up with new activities, challenges for students, use innovative methodologies, varied materials, etc.

Teachers from my point of view are entrepreneurs day by day.

This comment links entrepreneurship with education, but most noteworthy is the emphasis on innovative approaches, even in a field traditionally associated with a top-down, transmissive approach. Nonetheless, the field of education has slowly been changing, at least since the end of the twentieth century, when students came to be seen as protagonists in their own learning process. Summarising everything as a reply to the post by Group 3 is another question: "Isn't it about solving problems and acquire skills?"

Under the category "Entrepreneurship as a social and political phenomenon," we focus on just three representative posts. The first is an important reminder that "entrepreneurship is essentially made up of people and their values" (Group 6). This means that communication and interpersonal skills are essential for anyone who wants to thrive in our increasingly competitive business world, an idea which is also emphasised in the second post chosen to illustrate this cluster: "It is important that we remember that the world is run by people, hence it is so important that we try to understand the reason for their decisions before we judge them" (Group 9). While this post could be considered related to the traits of an entrepreneur, given that leadership is at stake, once again the crucial point focuses on communication and interpersonal relations.

The third post (Figure 7) asserts that if students do not identify with the subject matter being discussed, they simply disconnect. Despite its 26 likes and three reactions of love, the post received no verbal feedback from students.

Conversely, many posts and reactions dealt with the "Innate qualities predisposed to entrepreneurship." Firstly, the use of adjectives to describe soft skills and hard skills had been covered in Business English I, in the previous semester. Secondly, in our remote classes, the topics of sales and marketing, entrepreneurship, and franchises were among those examined. Consequently, students felt much more confident in discussing these topics, as they had familiarity with the relevant content, vocabulary and structures.

Determination and ambition are two qualities that are typically associated with an entrepreneurial mindset and Group 16 alluded to these traits, as shown in the post on the right. Several scholars - Bagheri and Pihie (2011), Baum et al. (2007), Daniel (2016), and Morris et al. (2008), and to name but a few - 


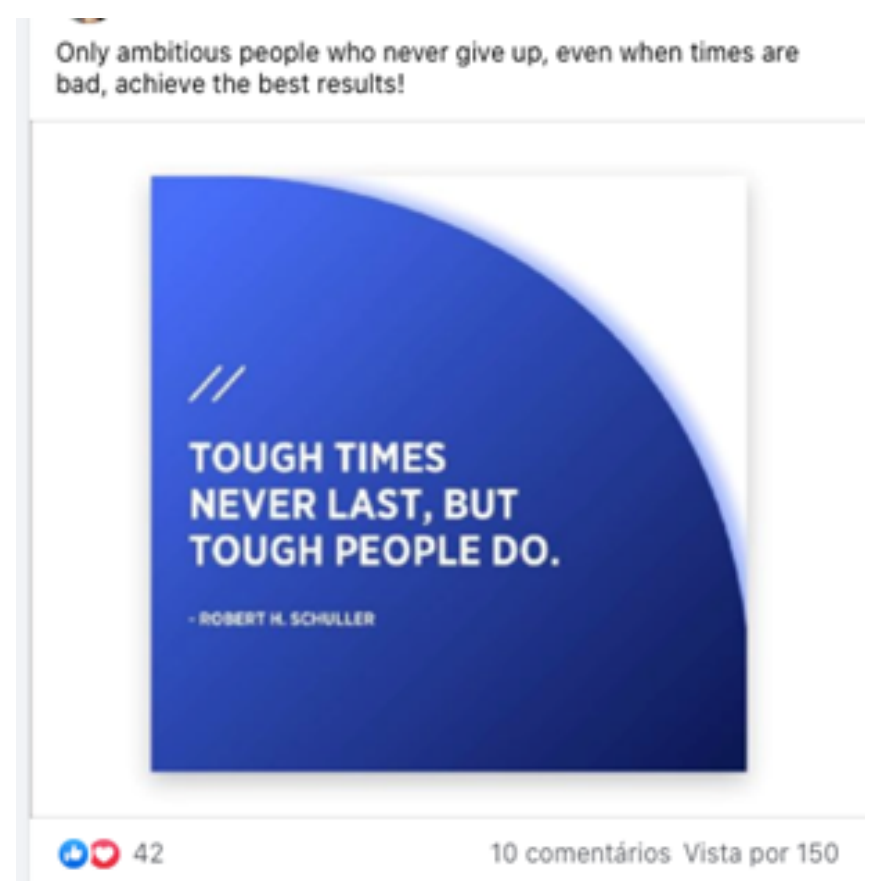

Figure 7. Post by Group 15 (Task 1).

have discussed what it takes to be an entrepreneur. Kouakou et al. (2019, p. 119), building on a study conducted by Cromie (2002), summarized it thus: "attributes such as the need for achievement, internal locus of control, calculated risk-taking, tolerance of ambiguity, creativity, need for autonomy and selfconfidence, are mainly connected to personality" (p. 119). The marketing students at the Polytechnic of Viseu likewise identified these as some of the main traits. In their words, perseverance and coherence are two particularly important features: "Patience and consistency is the key to success. Sooner or later the results appear, and they will be great!!" Boldness is similarly emphasised, as the following two comments make clear: "We only need 2 seconds of courage!" and "I think sometimes we just need an impulse, a little bit of courage, that could be given by a friend or someone special for us." Adopting a mental attitude of positive thinking, together with the aforementioned traits of self-confidence, determination, and boldness, is also cited as a hallmark of great entrepreneurs, in the following remark by Group 13:

We have to be positive and hope that a new beginning is the solution to many problems. Above all, we have to have willpower.

It is always good to keep this in mind when you are afraid to entrepreneur: if it doesn't work today, you can try again tomorrow. 


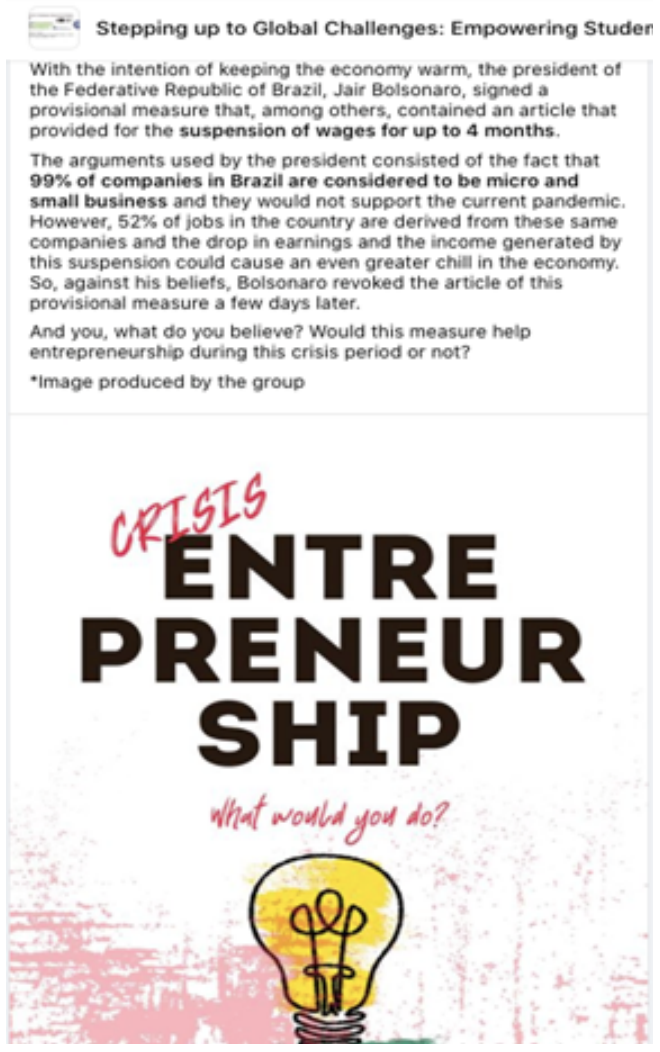

Figure 7. Post by Group 16 (Task 1).

Being an entrepreneur takes a lot of hard work, thus, research, some sacrifice, and self-discipline are also key ingredients to deal with the challenges entrepreneurs face. As Group 12 indicated, being tough is identified as a decisive attribute in determining the predisposition of entrepreneurs to undertake new projects, and to "achieve the best results," in Group 16's words, is not enough. On the contrary, it may well be synonymous with "hav[ing] a higher breaking point" (Group 12). "[P]utt[ing] in the work (...) [o]n rough days [when] everything is against you" is paramount to getting things done. Many comments supported this post, and added the idea of working toward being productive, while bringing value to the world. In fact, the concept of "being significant" is a motto taken from Oprah Winfrey, as seen in the following reaction: "Oprah Winfrey said: 'Don't worry about being successful but work toward being significant and the success will naturally follow." "The same idea was shared by students belonging to other groups, as these two posts convey: "Try not to become a man of success. Rather become a man of value," and "This is so true, if you give a worker the right conditions to work where he feels safe, motivated and valued he will always do better." 
30 de março $\cdot(-)$

partilhou uma ligaçăo.

It's not enough to have the best ideia, have the best team, have the best market, the best moment.

You have to put in the work, you have to develop a drive so high that even in rough days even everything is against you, things get done.

It's not enough to become tough because TOUGH just means you have a higher breaking point... you have to get ANTI-FRAGILE, meaning that no matter what hits you, you get up and you do what you woke up to do.

And that is the very definition of unstoppable.

"You can do anything you set your mind to, if you're willing to pay the price for greatness."

Tom Bilyeu

( Artur, Pedro, Paulo, Fátima)

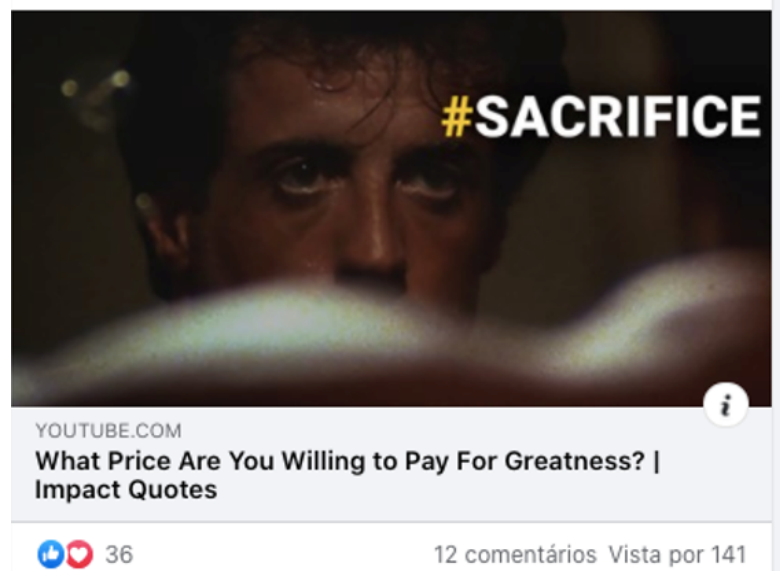

Figure 7. Post by Group 12 (Task 1).

Students' perspectives on entrepreneurship could be discussed at greater length, but the data analysis revealed how they advanced their repertoires of knowledge both on the topic, and the relevant vocabulary and grammar. This does not mean that there were not mistakes, though, as stated earlier, we viewed such errors as part of the students' progress. Bargiel-Matusiewicz \& Bargiel-Firlit $(2009$, p. 40$)$ remind us that "errors illustrate the patterns of learners' developing interlanguage systems and show where they have over-generalized a second language rule or where they have inappropriately transferred a first language rule to the second language." Throughout this study, we have quoted students' posts directly, and observed not only spelling mistakes, but also instances of ungrammatical utterances due to overgeneralisation, as in the following examples, of students' reactions to their peers' posts: "Even if anyone does't believe in you, the most important thing is believe in ourselfes!" (sic) and "Advices are good, actions are better!" (sic). In these two sentences, "does't" seems to be a typo, but "ourselfes" and "advices" simply follow the rules for adding a plural morpheme (-es or -s) to form the plurals of "ourself" and "advice." Of course, both plurals 
are irregular, the former because of the need to change the $-\mathrm{f}$ into a $-\mathrm{v}$ before the addition of -es and the latter because it is an uncountable noun and should thus remain unaltered. Moreover, evidence of interference from Portuguese can be observed in the use of the comparative, of the preposition "in" after the verb "to think," and in the splitting of infinitives in the following sentence: "I definitely agree, sometimes good things are more hard to get, but we need to think in our goals to never give up 3 ." Another mistake commonly found in students' posts and comments is subject-verb agreement, as the following statement exemplifies: "Sometimes the best part is not the results, it's the journey that lead us to our goal! Take it easy, enjoy the journey ." Less frequent, but also associated with students' difficulties is the correct choice of word categories. We noticed above the incorrect use of "entrepreneur" as a verb and observe below the use of the verb "succeed" where the adjective "successful" was the correct word category, as in: "That's totally true. We choose our paths, we decide our life and we decide what we are. And if we do it carefully but at same time spontaneously, we are going to be succeed."

One way of addressing these mistakes was to correct them indirectly in a reply "reformulati[ng (...)] the learner's incorrect utterance minus the error" (Puertas, 2018, p. 69), thus, using natural, visual, and almost immediate corrective feedback. Alternatively, similar sentences could be discussed in our Zoom lessons, involving metalinguistic explanations, so that students could then transfer this knowledge, spot mistakes, and self-repair. We noticed that students were much more open to expressing themselves when commenting on their peers' posts, probably because social media created a less formal environment for the task than traditional classes. Subscribing to Sirivedin et al.'s (2018, p. 184) findings, we realized that "through Facebook, learners with different amounts of experience and knowledge could interact with each other. They exchange information, ideas and knowledge, and help assess or edit each other comments while learning together."

\section{Conclusion}

In this study, we investigated the reactions of first-year Marketing students at the Polytechnic of Viseu to PBL teaching. In particular, we examined their choices and main language difficulties, as well as their interests and motivation to collaborate and share their knowledge with (inter)national peers. This focused on their will to learn and improve their skills in English, but also extended to the acquisition of other important skills related to communication, ICT, creativity, critical thinking, and problem solving.

As noted previously, we genuinely believe that ESP programs benefit from authentic communication. At a time when social distancing is necessary, such as during the current COVID-19 pandemic, technology and online platforms, 
as well as online social networking for teaching and learning, have become the alternative to the face-to-face activities formerly held in classes. Even though the international project 'SGC: Empowering Students across the World' was not foreseen as a response to the COVID-19 pandemic, it proved very effective not only in supporting student learning, but also in bridging the distance between students and teachers working remotely in Portugal, Turkey, and Poland.

Our findings indicate that students reflected upon the characteristics of entrepreneurship, associating it with education and with a process that often involves a long path to success. At other times, it may involve pure serendipity, taking courage, creativity, or a leap of faith. It may also be understood as a social and political phenomenon connected to innovation and problem solving. We also noticed that students felt more at ease learning English and making mistakes while using Facebook. This platform involved students in authentic situations, where they posted original work or quotations, pictures, or other information about entrepreneurship that they identified with, or wanted to contest.

Based on our analysis of the Facebook posts and the students' reactions to them, and supported to a limited extent by the general data gathered from online group meetings with international peers and from the students' final reports, we conclude that students had ample opportunity for reflection, collaboration, creativity, interaction, and language learning. They engaged in making sense of their own experiences, sharing, and discussing them with other students from different countries and fields of study, as well as with teachers who assumed the role of facilitators in the learning process at a time of great uncertainty. 


\section{Acknowledgments}

We would like to thank the Centre for Studies in Education and Innovation (CI\&DEI) and the Polytechnic of Viseu for their support.

\section{Conflict of Interest Disclosure}

The authors declare no conflicts of interest.

\section{Funding}

This work is funded by Apoios Especiais PV (http://politecnicodeviseu.info/ apoios-especiais/stepping-up-to-global-challenges-2/) and by National Funds through the FCT - Foundation for Science and Technology, I.P., within the Scope of the Project Ref. UIDB/05507/2020.

\section{Research Ethics Statement}

The authors declare that the manuscript constitutes their original work which has not been published or accepted for publication nor is it currently being considered for publication in another outlet. 


\section{References}

Allen, D. E., Donham, R. S., \& Bernhardt, S. A. (2011). Problem-based learning. New Directions for Teaching and Learning, 2011(128), 21-29.

Aydin, S. (2012). Areview of research on Facebook as an educational environment. Educational Technology Research and Development, 60(6), 1093-1106.

Bagheri, A., \& Pihie, Z. A. L. (2011). Entrepreneurial leadership: Towards a model for learning and development. Human Resource Development International, 14(4), 447-463.

Başöz, A. G. T., \& Aydin, S. (2011). An analysis on the grammatical mistakes made by advanced EFL writers. Humanities Sciences, 6(2), 296-306.

Bargiel-Matusiewicz, K., \& Bargiel-Firlit, A. (2009). Correction techniques preferred by students during the process of learning a foreign language. Psychology of Language and Communication, 13(1), 39-52.

Baum, J. R., Frese, M., \& Baron, R. A. (Eds.). (2014). The psychology of entrepreneurship. Psychology Press.

Blattner, G., \& Fiori, M. (2011). Virtual social network communities: An investigation of language learners' development of sociopragmatic awareness and multiliteracy skills. CALICO Journal, 29(1), 24-43.

Brassler,M.,\&Dettmers,J.(2017).How to enhanceinterdisciplinary competenceinterdisciplinary problem-based learning versus interdisciplinary projectbased learning. Interdisciplinary Journal of Problem-Based Learning, 11(2), $1-15$.

Cromie, S. (2000). Assessing entrepreneurial inclinations: Some approaches and empirical evidence. European Journal of Work and Organizational Psychology, 9(1), 7-30.

Dooly, M. (2017). Telecollaboration. In C. Chapelle, \& S. Sauro (Eds.), The handbook of technology and second language teaching and learning (pp. 169-183). John Wiley \& Sons.

Daniel, A. D. (2016). Fostering an entrepreneurial mindset by using a design thinking approach in entrepreneurship education. Industry and Higher Education, 30(3), 215-223.

Díaz, P., \& Ioannou, A. (2019). Learning in a digital world: An introduction. In P. Díaz, A. Ioannou, K. Bhagat, \& M. Spector (Eds.), Learning in a digital world: Perspective on interactive technologies for formal and informal education (pp. 1-12). Springer.

Giunta, C. (2017). An emerging awareness of generation $Z$ students for higher education professors. Archives of Business Research, 5(4), 90-104.

Godwin-Jones, R. (2019). Riding the digital wilds: Learner autonomy and informal language learning. Language Learning \& Technology, 23(1), 8-25.

Grabill, J. T., \& Hicks, T. (2005). Multiliteracies meet methods: The case for digital writing in English education. English Education, 37(4), 301-311.

Kouakou, K. K. E., Li, C., Akolgo, I. G., \& Tchamekwen, A. M. (2019). Evolution 
view of entrepreneurial mindset theory. International Journal of Business and Social Science, 10(6), 116-129.

Krüger, D., \& David, A. (2020). Entrepreneurial education for persons with disabilities - a social innovation approach for inclusive ecosystems. Frontiers in Education, 5, 1-17.

Levickaite, R. (2010). Generations X, Y, Z: How social networks form the concept of the world without borders (the case of Lithuania). LIMES: Cultural Regionalistics, 3(2), 170-183.

Leier, V. M. (2017). Learning language through Facebook. International Journal of Computer-Assisted Language Learning and Teaching, 7(3), 40-57.

Lo, S. K. (2008). The nonverbal communication functions of emoticons in computer-mediated communication. Cyberpsychology \& Behavior, 11(5), 595-597.

Magano, J., Silva, C., Figueiredo, C., Vitória, A., Nogueira, T., \& Pimenta Dinis, M. A. (2020). Generation Z: Fitting project management soft skills competencies - a mixed-method approach. Education Sciences, 10(7), 187.

Moran, S. (2010). The roles of creativity in society. In J. C. Kaufman, \& R. J. Sternberg (Eds.), The Cambridge handbook of creativity (pp. 74-90). Cambridge University Press.

Morris, M. H., Kuratko, D. F., \& Covin, J. G. (2008). Corporate entrepreneurship $\&$ innovation, entrepreneurial development within organisations. SouthWestern College Publishers.

Poláková, P., \& Klímová, B. (2019). Mobile technology and Generation Z in the English language classroom-A preliminary study. Education Sciences, 9(3), 203.

Puertas, T. H. (2018). Teacher's feedback vs. computer-generated feedback: A focus on articles. Language Value, 10, 67-88.

Promnitz-Hayashi, L. (2011). A learning success story using Facebook. Studies in Self-Access Learning Journal, 2(4), 309-316.

Reinhardt, J. (2019). Social media in second and foreign language teaching and learning: Blogs, wikis, and social networking. Language Teaching, 52(1), $1-39$.

Robinson, K. (2006). Do schools kill creativity? [Video]. TED Conferences. https://www.ted.com/talks/ken_robinson_says_schools_kill_creativity

Scarborough, N., \& Cornwall, J. (2015). Inside the entrepreneurial mind: From ideas to reality. In T. W. Zimmerer, N. Scarborough, \& D. Wilson (Eds.), Essentials of entrepreneurship and small business management (pp. 96146). Pearson Global Editions.

Schwandt, T. (2000). Three epistemological stances for qualitative inquiry: Interpretivism, hermeneutics, and social constructionism. In N. Denzin, \& Y. Lincoln (Eds), Handbook of qualitative research (pp. 189-213). Sage.

Seemiller, C., \& Grace, M. (2017). Generation Z: Educating and engaging the next generation of students. About Campus, 22(3), 21-26. 
Sirivedin, P., Soopunyo, W., Srisuantang, S., \& Wongsothorn, A. (2018). Effects of Facebook usage on English learning behavior of Thai English teachers. Kasetsart Journal of Social Sciences, 39(2), 183-189.

Vizcaya-Moreno, M. F., \& Pérez-Cañaveras, R. M. (2020). Social media used and teaching methods preferred by generation $\mathrm{z}$ students in the nursing clinical learning environment: A cross-sectional research study. International Journal of Environmental Research and Public Health, 17(21), 8267. 